\title{
Acolhimento psicológico em situação de crise suicida: relato de experiência
}

\author{
Psychological reception in a suicidal crisis situation: an experience report
}

Atención psicológica en situación de crisis suicida: relato de experiencia

Recebido: 03/10/2021 | Revisado: 10/11/2021 | Aceito: 11/11/2021 | Publicado: 20/11/2021

Geovana Vargas Casarin

ORCID: https://orcid.org/0000-0002-4190-7771

Universidade Franciscana, Brasil

E-mail: geovanacasarin@gmail.com

Gabriela Maffini

ORCID: https://orcid.org/0000-0001-9130-4699

Universidade Franciscana, Brasil

E-mail: gabriela.maffini1@gmail.com

Paula Argemi Cassel

ORCID: https://orcid.org/0000-0003-2556-4067

Universidade Franciscana, Brasil

E-mail: Paula.acassel@gmail.com

Félix Miguel Nascimento Guazina

ORCID: https://orcid.org/0000-0002-1683-2317

Universidade Franciscana, Brasil

E-mail: guazina@gmail.com

Cristiane Bottoli

ORCID: https://orcid.org/0000-0002-5928-3805

Universidade Franciscana, Brasil

E-mail: cbottoli@hotmail.com

\begin{abstract}
Resumo
O suicídio é um fenômeno que se faz presente dentro de uma totalidade mundial, considerado como a terceira principal causa de morte entre jovens de 15 a 19 anos. A discussão sobre o tema é necessária, principalmente dentro dos cursos de graduação de Psicologia, de forma a equipar o profissional teoricamente, para que este consiga dar conta das questões que surgem na prática. Este artigo tem por objetivo relatar a experiência de uma intervenção psicológica realizada a uma paciente qual encontrava-se em crise, após tentativa. Trata-se de um relato de experiência, de caráter qualitativo. Constata-se a necessidade de que o atendimento seja demarcado pela postura acolhedora e empática do terapeuta, para que o paciente se sinta amparado. Este tipo de intervenção possui como objetivo proporcionar apoio ao paciente, estabelecer medidas de segurança a sua integridade física, reduzir o risco de tentativa posterior e realizar encaminhamentos para serviços necessários.
\end{abstract}

Palavras-chave: Suicídio; Intervenção na crise; Psicologia.

\begin{abstract}
The discussion of the theme is necessary, mainly within the Psychology undergraduate courses, in order to equip the professional theoretically, so that they can deal with the issues that arise in practice. This article aims to report the experience of a psychological intervention performed on a patient who was in a suicide crisis, after an attempt. This report of professional experience has a qualitative nature. There is a need for the service to be marked by the therapist's welcoming and empathetic posture, so that the patient feels supported. This type of intervention aims to provide support to the patient, establish safety measures for their physical integrity, reduce the risk of further attempt and make referrals to the necessary services.
\end{abstract}

Keywords: Suicide; Crisis intervention; Psychology.

\section{Resumen}

El suicidio es un fenómeno que está presente dentro de una totalidad global, considerado como la tercera causa de muerte entre los jóvenes de 15 a 19 años. La discusión sobre el tema es necesaria, principalmente dentro de los cursos de graduación de Psicología, con el fin de equipar teóricamente al profesional, para que pueda abordar las cuestiones que se presentan en la práctica. Este artículo tiene como objetivo relatar la experiencia de una intervención psicológica realizada a un paciente que se encontraba en crisis tras un intento. Es un relato de experiencia, con carácter cualitativo. Es necesario que la atención esté delimitada por la postura acogedora y empática del terapeuta, de modo que el paciente se sienta apoyado. Este tipo de intervención tiene como objetivo brindar apoyo al paciente, establecer medidas de seguridad para su integridad física, reducir el riesgo de un intento posterior y realizar derivaciones a los servicios necesarios.

Palabras clave: Suicidio; Intervención de crisis; Psicología. 


\section{Introdução}

O suicídio é definido pela Organização Mundial da Saúde (OMS) (2019) como um problema de saúde mental altamente relevante, estando entre as 20 principais causas de morte mundiais. Ocorrem em média, anualmente, 800 mil mortes por suicídio, sendo considerado como a terceira principal causa de morte entre jovens de 15 a 19 anos de idade (World Health Organization, 2019).

No Brasil, os dados registrados pelo Sistema de Informações sobre Mortalidade (SIM) demonstrou que, entre os anos de 2007 e 2016, houve 106.374 óbitos por suicídio (Brasil, 2018). É evidenciado que a taxa de suicídio vem aumentando no país a cada ano de forma sistemática, pois, a partir de dados comparativos liberados pelo Ministério da Saúde, percebeu-se um aumento significativo, uma vez que, em 2009, a cada 100 mil habitantes, a taxa era 4,1 (Brasil, 2009) enquanto em 2016, a taxa encontravase em 5,8 (Brasil, 2018).

O suicídio é um fenômeno que se faz presente em todas as regiões do mundo, ocorrendo independente de condições socioeconômicas, culturais ou religiosas (Organização Pan-Americana Da Saúde, 2018). Apesar disto, percebe-se que há uma variação na predominância de gênero, sendo constatado que em países desenvolvidos, homens apresentam um número três vezes maior de mortes por suicídio, enquanto em países em desenvolvimento, o número óbitos é superior em mulheres (Palmas, Santos, \& Ignotti, 2020).

É pertinente discutir acerca do suicídio, uma vez que não existe um único fator de causalidade, podendo ser resultado de uma interação de diversos fatores, sendo estes biológicos, temperamentais, genéticos, culturais e ambientais, o que gera grande complexidade na compreensão do comportamento suicida (OMS, 2000; Conselho Federal De Psicologia, 2013). O suicídio é um sintoma de diversos transtornos mentais, no entanto, sabe-se que há indicadores de predisposição ao suicídio, com maior incidência em pacientes com transtorno de humor bipolar (Yatham et al., 2018), depressão (Barbosa, Macedo, \& Silveira, 2011), dependência a substâncias (Bohnert, Ilgen, Louzon, McCarthy, \& Katz, 2017), esquizofrenia (Sher \& Kahn, 2019) e determinados transtornos de personalidade (Botega, 2015, Gooding et al., 2020).

A existência de uma tentativa anterior de suicídio é considerada como alto risco da possibilidade de concretização do suicídio consumado (WHO, 2019; Brasil, 2020). Ainda, outro forte indicador, são pacientes que apresentam estresse psicológico provenientes de situações adversas. Pacientes que apresentam ideação suicida tendem a possuir dificuldade na resolução de problemas, se vendo incapaz de contornar seus conflitos (Hawton et al., 2016).

Há diferentes denominações na literatura que fazem parte do espectro suicida, incluindo ideação suicida, com ou sem plano de execução, tentativa de suicídio e suicídio consumado (Werlang, Borges, \& Fensterseifer, 2005; Tureki et al., 2019). A ideação suicida é definida como o pensamento sobre o ato, o considerar, o planejamento e a elaboração do plano, enquanto a tentativa é um comportamento não fatal, embora não livre de consequências físicas ou emocionais, autodirigido com a intenção de morte. O suicídio consumado é o óbito por comportamento autolesivo intencional que acaba por ser fatal (Klonsky, May, \& Saffer, 2016; Tureki et al., 2019).

As reações de um indivíduo em situação de emergência geralmente têm cargas emocionais intensas, compatíveis com o momento que o paciente se encontra (Sá, Werlang, \& Paranhos, 2008). Em muitos casos, apenas após a tentativa de suicídio que o paciente tem o primeiro contato com um profissional de saúde mental (Gondim, 2015), sendo imprescindível oferecer assistência ao paciente, avaliando as demandas e encaminhando para serviços necessários.

Ao acompanhamento psicológico com pacientes em crise suicida, o profissional deve proporcionar suporte, demonstrando empatia, presença genuína, disponibilidade afetiva e de tempo, clareza das suas responsabilidades bem como o limite das mesmas 
Research, Society and Development, v. 10, n. 15, e74101522769, 2021

(CC BY 4.0) | ISSN 2525-3409 | DOI: http://dx.doi.org/10.33448/rsd-v10i15.22769

(Botega, 2015). A elaboração de um plano de segurança com pacientes com alto risco, assim como o estabelecimento de um "contrato de não suicídio" são fundamentais. A atenção para a disponibilidade de possíveis meios letais também é necessária, a fim de preservar a segurança do paciente. Da mesma forma, o acompanhamento de um familiar ou responsável é indispensável (Sousa Filho, Kanomata, Feldman, \& Maluf Neto, 2017).

No plano de segurança, também denominado de plano de crise, elabora-se um documento em conjunto pelo paciente e psicólogo, o qual possui a intenção de auxiliar que os pacientes controlem seus impulsos de irem ao ato, permitindo que exista tempo para a valência destes pensamentos diminuírem. Neste documento é obrigatório a indicação de possíveis gatilhos, com sugestões de intervenções de regulação emocional, além de formas de acesso a pessoas que podem ofertar apoio, informações como contatar o/a psicólogo/a, psiquiatra e/ou outros serviços (Wright, Brown, Thase, \& Basco, 2019).

O contrato de não-suicídio consiste em estabelecer junto ao paciente, combinações verbais referentes ao estabelecimento de comportamentos visando a regulação emocional, e o contato com o terapeuta quando houver a tentativa de autolesão (Maia, Rocha, Araújo, \& Maia, 2017). Esse tipo de técnica é usada de forma complementar a outras, como resultado, na maioria dos casos, o respeito pelo combinado. Entretanto, para a sua efetividade, existem fatores adjuntos que a influenciam, como a existência de uma relação terapêutica e a compreensão e discernimento que o paciente tem das consequências de suas ações (Bertolote, Mello-Santos \&, Botega, 2010).

O manejo com paciente em crise suicida envolve não apenas o trabalho individual do psicoterapeuta, mas sim o trabalho interdisciplinar, em conjunto com outros profissionais da área da saúde, além dos familiares, responsáveis e relacionamentos afetivos, visando a segurança do paciente em todos os aspectos do contexto diário. Por vezes, elabora-se um contrato de responsabilização dos cuidados do paciente para este ser liberado pelo psicoterapeuta, sendo necessária a nomeação de um responsável. Ao ser contatado o responsável, há a explicação da importância da psicoterapia, da busca por atendimento psiquiátrico e da precaução com materiais que podem apresentar risco ao paciente como objetos cortantes, medicamentos, armas de fogo, entre outros (Wenzel, Brown, \& Beck, 2010).

Há uma grande demanda na área da Psicologia Clínica referente ao atendimento a pacientes em risco de suicídio, pois este fenômeno apresenta grande complexidade, sendo necessário que o profissional tenha conscientização da importância sobre o estudo nesta temática. A compreensão deste fenômeno permite que ocorra uma intervenção mais efetiva, promovendo assistência da qual o paciente demanda (Conselho Federal De Psicologia, 2013).

Embora haja avanços no conhecimento da temática do suicídio e o atendimento em crise, é incipiente as disciplinas que abordam na graduação essas temáticas especificamente e que deem suporte teórico, epistemológico e técnico para lidar com essas questões. Diante dessas considerações este artigo objetiva relatar a experiência de uma intervenção psicológica, realizada por uma psicóloga e duas estagiárias em psicologia clínica, a uma paciente que se encontrava em momento de crise suicida, logo após tentativa de suicídio. O atendimento efetuado ocorreu a partir do serviço-escola em Psicologia em uma universidade privada, localizada no interior do Rio Grande do Sul.

\section{Metodologia}

Trata-se de um relato de experiência profissional, de caráter exploratório e descritivo, caracterizado por ser uma pesquisa qualitativa. Este estudo aborda uma intervenção realizada, a partir de um serviço-escola de Psicologia, a uma paciente do sexo feminino que estava em crise suicida. O serviço-escola tem seu funcionamento vinculado a uma universidade particular localizada no interior do Rio Grande do Sul. Estes desempenham um importante papel pois proporcionam a comunidade, tanto acadêmica 
quanto ao público exterior, a possibilidade de acesso a atendimentos psicológicos por baixo custo (Peres, Santos, \& Coelho, 2004). Nesse sentido, os serviços-escola ocupam uma centralidade na formação da Psicologia, uma vez que seu objetivo é a construção de um saber clínico a partir da relação entre os sujeitos que precisam de atendimento psicológico e os fatores sociais, econômicos e políticos de um determinado contexto. Dessa forma, seu objetivo é tensionar e ampliar as diferentes formas de exercício da clínica para além da lógica do consultório privado (Fam \& Ferreira Neto, 2019).

Define-se por relato de experiência, uma descrição da vivência profissional, escrita por um ou mais autores, de grande importância para a aquisição do conhecimento acadêmico, proporcionando discussões, reflexões e análise de recursos que visam estabelecer melhorias para o cuidado em saúde (Flick, 2004). A escolha da metodologia adotada está relacionada com a possibilidade de haver aprofundamento acerca do tema, permitindo que ocorra maior conhecimento sobre as intervenções a pacientes em crise suicida.

Esta pesquisa possui cunho qualitativo, tendo o seu foco principal na análise e na obtenção dos dados para futura compreensão e interpretação destes, sendo caracterizada por ser um tipo de metodologia que leva em consideração a subjetividade do autor nos resultados da pesquisa (Gil, 2002). É necessário que os pesquisadores tenham percepção acerca da influência da presença de subjetividade nos resultados da pesquisa realizada, devendo utilizar da autorreflexão para compreender suas interferências na interpretação e coleta de dados, estando atentos aos vieses que possuem (Patias, \& Hohendorff, 2019).

Para a construção do referencial teórico desta pesquisa, foram utilizados livros de autores considerados como referências nas temáticas de suicídio e prevenção, cartilhas, documentos informativos, além de serem utilizados artigos científicos de forma complementar. Foram realizadas consultas nas plataformas digitais da Pepsic (Periódicos Eletrônicos de Psicologia), Google Acadêmico (GoogleScholar), Scielo (Scientific Eletronic Library Online) e PubMed (MedLine Database), utilizando como palavraschaves na busca os termos "Suicídio", "Suicide", "Manejo em crise suicida", "Suicidal crisis management", "Relato de Experiência", "Experience Report", "Psicologia", "Psychology" e termos variáveis destes, não havendo restrição de datas, utilizando de estudos que estivessem na língua portuguesa e inglesa.

A participante deste estudo é uma jovem adulta, de 21 anos, denominada para este artigo de Helena (nome fictício), estudante de graduação da mesma universidade. A paciente assinou o Termo de Consentimento Livre e Esclarecido (TCLE) permitindo a realização de registros em prontuários, relatos em supervisões e elaboração de estudos e pesquisas, com a restrição de que possíveis identificadores fossem mantidos em sigilo. Todos os participantes deste estudo receberam nomes fictícios a fim de preservar a identidade e seguir os princípios éticos necessários para a elaboração deste estudo. Ainda, a psicóloga participante na intervenção, era supervisora do serviço-escola e as duas estagiárias em Psicologia Clínica encontravam-se, no momento da intervenção, no quarto ano do curso de Psicologia.

\section{Resultados e Discussão}

Os resultados se referem a um relato de experiência a partir da atuação de uma intervenção psicológica para manejo de crise suicida, realizada a uma paciente. Helena ${ }^{1}, 21$ anos, estudante de curso superior de uma instituição privada, realizou tentativa de suicídio. Como consequência, o serviço-escola de Psicologia da instituição foi acionado de forma emergencial para que fosse feito um acolhimento e intervenção psicológica com a paciente.

\footnotetext{
${ }^{1}$ Nome fictício.
} 
Research, Society and Development, v. 10, n. 15, e74101522769, 2021

(CC BY 4.0) | ISSN 2525-3409 | DOI: http://dx.doi.org/10.33448/rsd-v10i15.22769

Aspectos quanto ao estado mental da paciente foram observados e destacados. Dentre eles, sua aparência, onde fazia uso de roupas como moletom, em um dia de calor. Seu estado de consciência caracterizava-se como hiperalerta, pois a mesma estava ansiosa, com respostas aumentadas aos estímulos externos como, por exemplo, barulhos. Sua afetividade era incongruente em relação ao que estava sendo relatado, pois tratava com humor a sua ação de tentativa de suicídio. Além disso, apresentava atitude ambivalente relacionado à figura materna, havendo por vezes falas com desejo de ficar só e por outras, com desejo de ser amparada, apresentando emoções simultaneamente incompatíveis. Cardoso, Donato e Zanetti (2015) afirmam que através da observação é possível explorar melhores estratégias para comunicar-se com o paciente e também aferir dados objetivos do relacionados à aparência, comportamento, interação com o meio, entre outros aspectos que auxiliaram no processo de cuidado.

A avaliação ocorreu através do protocolo de entrevista e observação clínica de avaliação e manejo da crise suicida em paciente de clínica-escola de Psicologia (Martins \& Cassel, 2019), sendo constatado que a paciente apresentava alto risco de suicídio. No protocolo elaborado, existem três denominações para caracterização de risco, sendo estes, risco baixo, moderado e alto. Conforme o estabelecido pelos autores supracitados, considera-se pacientes de alto risco os que apresentam tentativa de suicídio anterior, depressão grave e/ou alucinações, abuso de substâncias, desespero, tormento psíquico intolerável, plano definido de suicídio, possuindo meios em como fazer ou pacientes que tomaram providências para o ato.

Para os autores Wenzel et al. (2010), os fatores de risco para comportamento suicida estão associados a existência de histórico psiquiátrico, variáveis psicológicas como a desesperança, cognições relacionadas ao suicídio, aumento da impulsividade, déficits na resolução de problemas, perfeccionismo e principalmente, existência de tentativa de suicídio anterior. Ainda que estes fatores aumentem a vulnerabilidade e a tendência dos comportamentos, é a combinação destes que influenciam a tomada de decisão do paciente.

Para a realização da intervenção, foram até o local duas estagiárias plantonistas do serviço-escola e uma psicóloga clínica, supervisora clínica, com o intuito de intervir, acolher e amparar a paciente. Helena encontrava-se em uma sala acompanhada por funcionários da instituição, e em primeiro momento apenas a psicóloga entrou na sala em que Helena encontrava-se, a fim de compreender a situação.

Ao pedir autorização para conversar com a paciente, a psicóloga demonstra estar a sua disposição, pois, ao não haver imposições do que irá ser feito, permite que o paciente consiga conectar-se com o terapeuta, sentindo-se validado e escutado. O sujeito que tentou suicídio, necessita de alguém para confiar, sendo de suma importância o estabelecimento de vínculo entre terapeuta-paciente (Zana \& Kovács, 2013) e que o profissional demonstre estar disposto afetivamente a ouvi-lo e ajudá-lo.

O conhecimento da história prévia do paciente, auxiliando a identificar os seus pensamentos e possíveis gatilhos, são de suma importância para a prevenção do ato e proteção do paciente (Osteen, Frey \& Ko, 2014). Ao acolher a paciente, descobriu-se que além da tentativa de suicídio na própria situação de atendimento, houve tentativa de suicídio com outro método (medicamento) datada em um ano anterior, além de apresentação de planejamento com execução estabelecida para quando saísse do local, bem como tormento, desesperança e labilidade emocional.

Por esta razão, a intervenção psicológica pontual e acompanhamento psicológico posterior se fez de grande importância para promoção de saúde da paciente. Em momento de crise suicida, a intervenção possui o seu foco na prevenção imediata e não em resolver todos os fatores que levaram o paciente a cometer o ato (Colucci, Kelly, Minas, Jorm, \& Nadera, 2010) sendo fundamental o profissional oferecer uma escuta sensível para compreender quais os fatores que levaram o paciente a tentativa (Conselho Federal De Psicologia, 2013). 
Durante a conversa inicial, a psicóloga deixou a paciente expressar-se, sendo isto definido por Botega (2015), como detentor de grande valor terapêutico, pois a partir da adoção de uma conduta receptiva de não julgamento, proporciona-se ao paciente a segurança para dividir seus pensamentos e emoções. Apenas posteriormente a saída dos funcionários que as estagiárias do serviço tiveram acesso a sala em que Helena se encontrava, visando reduzir possíveis desconfortos a mesma em relação ao número de pessoas.

Inicialmente, a paciente apresentou negação ao ser questionada sobre o ocorrido, utilizando como estratégia, sarcasmo para se referir sobre suas ações anteriores. Existem pacientes que verbalizam e demonstram de forma clara o seu elevado potencial suicida, em comparação a outros, que diante questionamentos, apresentam-se tranquilos rapidamente, podendo transmitir uma falsa impressão de estabilidade (Rocha \& Araújo, 2018). No caso de Helena, falas como "não estava fazendo nada, estava querendo tomar um ar", seguidas de risadas e piadas eram comuns, apresentando estratégia de enfrentamento de esquiva, associada à desregulação emocional.

Conforme o acolhimento das necessidades emocionais da paciente, aceitação e valorização das suas emoções, Helena revelou que a razão da tentativa de suicídio estava associada a necessidade de aliviar a dor de sentimentos advindos de um relacionamento amoroso conturbado. Como indicadores de potencial suicida, destaca-se que o estresse ambiental ocasionado por eventos recentes como perdas interpessoais, términos de relacionamentos, conflitos e outras situações de cargas emocionais elevadas, podem aumentar o risco de suicídio (Wright et al., 2019).

A paciente manifestava impaciência e forte desejo de se retirar do ambiente universitário, apresentando uma alta reatividade com apresentação de agitação motora, fala acelerada, oscilação emocional, despersonalização e respostas de sobressalto diante a barulhos. Compreendendo a desregulação de Helena, a psicóloga psicoeducou-a sobre as suas reações. A psicoeducação é uma técnica de grande importância na intervenção, pois permite o paciente compreender, em diversos aspectos, as consequências de seus comportamentos disfuncionais, devendo ocorrer de forma didática para que o paciente tenha melhor entendimento (Nogueira, Crisostomo, Souza, \& Prado, 2017; Oliveira \& Dias, 2018).

A postura das estagiárias e da psicóloga durante o acolhimento visaram o estabelecimento de confiança para que a paciente se sentisse aceita e pertencida, com demonstração de respeito por seus desejos, possibilitando que a paciente conseguisse expressar suas emoções de forma legítima. A ausência de criticismo permite que o paciente compartilhe sobre as áreas de conflito pessoais, proporcionando maior compreensão sobre o que desencadeou a tentativa de suicídio. Ao mesmo tempo em que se direcionou de empatia e suporte a paciente, houve firmeza e assertividade nas orientações do que deveria ser feito para mantê-la segura.

É fundamental que o psicólogo trabalhe com honestidade com o paciente, pois o estabelecimento de vínculo só é possibilitado se há presença de veracidade sobre as medidas de segurança que serão adotadas e sobre as decisões que serão tomadas, assim como a razão destas. A falta de confiança no psicólogo implica em consequências negativas ao paciente, impedindo que o mesmo se sinta à vontade para confidenciar suas emoções e seus conflitos interiores (Zana \& Kóvacs, 2013).

Destaca-se a importância do psicólogo estar disponível para auxiliar o paciente, tendo em mente que o paciente em crise suicida, encontra-se em estado de desesperança e sofrimento, com dificuldade em dar sentido ao sofrimento, havendo falta de recursos para enfrentar sentimentos e situações (Maia et al., 2017). Ainda, se faz necessário que o ambiente utilizado seja possível de garantir o sigilo. Apesar da necessidade de ser um ambiente mais restrito, na sala utilizada houve a entrada de funcionários da instituição em determinados momentos, devido estes terem sido acionados anteriormente a chegada do serviço de Psicologia, podendo ser considerado um fator delimitante a intervenção.

Para a liberação do paciente que apresenta forte ideação suicida, planos ou tentativas, é necessário que haja a nomeação de um responsável, necessitando ser alguém que conviva com o paciente de forma diária e possa assegurar medidas de proteção. 
Normalmente, o nomeado é um familiar pelo convívio diário, entretanto, a rede de apoio pode ser mais extensa, havendo a possibilidade de nomeação de outros responsáveis, sem necessidade de laços consanguíneos, desde que seja alguém que consiga proteger e dar segurança ao mesmo.

Por parte de Helena, apesar do desejo em retirar-se do ambiente, havia forte recusa em nomear um familiar para que pudesse responsabilizar-se pela sua segurança, sendo descoberto que a mesma residia apenas com a mãe de forma parcial, não havendo outro familiar imediato. $\mathrm{O}$ trabalho voltado à prevenção ao suicídio ocorre em conjunto a família, devendo ser apontados contatos considerados pelo paciente como sua rede de apoio, de forma que, diante a crise, o psicólogo possa acessar os indicados para manter o paciente a salvo (Fukumitsu, 2014).

Houve relutância da parte de Helena para que fosse chamado sua mãe, pois a mesma afirmava que ela não saberia dar o suporte necessário, devido a tendência ao choro diante situações adversas. Ainda apresentando uma conduta empática, a psicóloga validou seus sentimentos, entretanto, realizou uma intervenção, destacando que o fato da mãe chorar diante os problemas da filha, pode ser o único recurso disponível naquele momento, entretanto, não significaria que a mesma não estivesse disposta a estar do seu lado.

O Conselho Federal de Psicologia (2005) preconiza que o psicólogo possui como dever fundamental, manter o sigilo as demandas e necessidades do paciente. Entretanto, diante a crise suicida, é considerada a possibilidade de decisão de quebra do sigilo, no que diz respeito aos princípios fundamentais da ética profissional, visando a saúde do paciente (Zana \& Kovács, 2013; Botega, 2015). Helena apresentava forte recusa em nomear um familiar por preocupação de que não pudessem auxiliá-la. Contudo, ressaltase que mesmo em desacordo com o paciente, é necessário o contato com um familiar, tendo em vista o objetivo de criar uma rede de proteção ao paciente (Conselho Regional De Psicologia Do Rio Grande Do Sul, 2019).

A quebra de sigilo nesta situação é justificada pela necessidade de haver alguém para prestar assistência 24 horas para a paciente, visando a manter em local seguro, livre de materiais que apresentassem risco a sua vida. Desta forma, uma das funcionárias do local, se propôs então, de ir buscar a mãe da aluna, já que não foi possível obter o seu contato.

Nesse momento, Helena ficou acompanhada de uma das estagiárias, visto que, pacientes em crise não podem ficar sozinhos. Durante o momento a sós com Helena, a estagiária ressaltou a importância de que fosse chamado sua mãe, pois era quem convivia com Helena mais tempo, sendo então a pessoa mais indicada para acompanhá-la na volta para casa. Também afirmou que tanto a psicóloga quanto as estagiárias visavam o seu bem-estar e estavam dispostas a amparar tanto ela quanto a mãe naquele momento.

Percebeu-se então, que foi estabelecido uma relação de confiança da paciente com a estagiária, confidenciando-a de que já havia tido tentativa de suicídio anteriormente por overdose de medicamentos. O terapeuta deve tentar entender mais detalhes, como antecedentes específicos aos pensamentos suicidas ou qualquer histórico de outros comportamentos autolesivos (Friedberg \& Mcclure, 2019). Compreendendo a importância do fato contado por Helena, a estagiária questionou se ela havia compartilhado com a psicóloga essa informação e diante resposta negativa, perguntou se seria possível a mesma confidenciar o acontecimento à profissional.

A estagiária retomou com a paciente a informação da sua tentativa de suicídio anterior na presença da psicóloga, o que resultou no conhecimento de que havia um plano de suicídio com execução elaborada. Entretanto, afirmava que não se sentia confortável em dividir com todas ali presentes, ficando na sala apenas a profissional e a estagiária a qual já havia confidenciado. O plano consistia em cometer suicídio atirando-se de uma ponte, a qual localizava-se perto de sua residência. Os planos de suicídio e o acesso do paciente aos meios potencialmente letais são componentes especialmente importantes de receberem atenção, pois a partir destes, que o paciente e responsável podem auxiliar a manter a sua segurança (Wright et al., 2019). 
Enquanto a conversa supracitada ocorria, a mãe de Helena chegou juntamente à funcionária da instituição a qual ficou responsável por buscá-la. A estagiária que estava fora da sala recebeu a mãe, percebendo que a mesma apresentava idade avançada e condições precárias de saúde, sendo este um fator de preocupação com a segurança da paciente. Diante a chegada da mãe, a psicóloga a informou sobre o ocorrido e orientou a mesma sobre as medidas de proteção a serem adotadas, como a retirada de materiais de risco como armas brancas, remédios, álcool, armas de fogo, sendo fundamental evitar deixá-la desacompanhada.

A mãe assinou o termo de responsabilidade declarando estar inteiramente responsável por prestar assistência 24 horas. Entretanto, tomou a decisão de que a filha iria passar a tarde e à noite aos cuidados das amigas citadas anteriormente, por acreditar que seria mais bem cuidada por elas. Por este fato, foi entrado em contato com ambas para assegurar o combinado e garantir que Helena fosse mantida em segurança.

Botega (2015) define que a psicoterapia do paciente em crise suicida divide-se em dois tempos, sendo o primeiro onde são empregadas técnicas de apoio, aliadas a psicofármacos e em segundo momento, é necessária uma psicoterapia de longo prazo. Durante a intervenção, houve contato com um médico responsável pela Psiquiatria de um hospital público da cidade para que a mesma pudesse ser atendida, visto que, não possuía condições socioeconômicas para atendimento particular. O trabalho multidisciplinar é de suma importância para auxiliar o paciente a adquirir um funcionamento mais adaptativo e saudável, visando o seu bem-estar (Fukumitsu, 2014).

Entendendo a necessidade da psicoterapia a longo prazo, após a orientação de ser um pré-requisito para haver continuidade do tratamento, a paciente verbalizou preferência por atendimento por uma das estagiárias ali presentes. Percebe-se então a importância do vínculo no atendimento, sendo evidenciado na escolha de Helena pela estagiária a qual confidenciou o plano de suicídio e ficou por maior tempo a sós. Para que isso ocorresse, a paciente assinou o Termo de Consentimento Livre e Esclarecido (TCLE), qual é necessário segundo as normas da instituição para que ocorra atendimento psicológico.

A intervenção subsequente a tentativa de suicídio, referente a primeira assistência psicológica ao paciente, tem duração variável de tempo, podendo durar de minutos a horas (Sá, Werlang, \& Paranhos, 2008). A intervenção realizada com Helena teve a duração aproximada de duas horas, levando em consideração as necessidades emocionais da paciente, o tempo de acolhimento, psicoeducação, contato com amigas e chegada da responsável para liberação.

Considera-se que a intervenção em momento de crise suicida possui como principais objetivos proporcionar apoio ao paciente, reduzir o risco de suicídio, compreender a rede de apoio para que esteja em segurança, além de possuir como intuito aliar o paciente com recursos de ajuda disponíveis (Sá, Werlang, \& Paranhos, 2008). No atendimento a pacientes com este tipo de risco, é necessário que o terapeuta esteja atento a sinais de desregulação emocional e desesperança, estando disponível a ele, de forma que este seja amparado, escutado e validado.

Diante a uma postura de não julgamento por parte do terapeuta, o paciente consegue sentir-se confortável para compartilhar seus sentimentos e pensamentos. Ainda, destaca-se que o terapeuta deve estar disposto tanto emocionalmente quanto fisicamente, compreendendo que este tipo de atendimento possui determinadas particularidades provenientes da situação de carga emocional elevada em que o paciente se encontra.

Os atendimentos psicoterápicos posteriores foram realizados na clínica escola da instituição e tiveram início no dia seguinte ao acolhimento. Os encontros foram feitos semanalmente com a estagiária designada à qual foi estabelecido maior vínculo. Foi disponibilizado o contato telefônico pessoal à paciente e rede de apoio, tendo em vista o alto risco do caso e possíveis emergências. Por esse fato, durante o período de psicoterapia presencial, houve também, acolhimentos remotos quando necessário. 


\section{Considerações Finais}

Este artigo teve por objetivo apresentar, a partir de um relato de experiência, uma intervenção realizada a uma paciente em crise suicida, por duas estagiárias e uma psicóloga vinculadas a um serviço-escola, visando exemplificar o manejo realizado. Diante dessa pesquisa, ressalta-se a importância de compreender a tentativa de suicídio como um fenômeno multifatorial, o qual pode ter influência de transtornos mentais graves, situações estressoras adversas, além de haver como forte indicador de possibilidade de tentativa, histórico anterior.

Ao ser realizada a intervenção e acompanhamento a pacientes em crise suicida, é necessário que o profissional demonstre empatia, disponibilidade afetiva e temporal, utilizando de técnicas comportamentais como a elaboração de um plano de segurança, do contrato de não-suicídio, além de recorrer a familiares do paciente para que este seja protegido. Ademais, destaca-se a importância de haver o trabalho multidisciplinar, tendo em vista que, pacientes em crise apresentam elevadas cargas emocionais, podendo ser necessário que ocorra trabalho em conjunto entre a Psicologia e a Psiquiatria.

Ainda, os atendimentos a estes pacientes apresentam dificuldades, tendo em vista a grande oscilação emocional que estes encontram-se. Com isso, pode haver recusa e negação do paciente em nomear familiares ou responsáveis. Nesse sentido, a quebra do sigilo profissional é justificada e embasada pelo próprio Conselho Federal de Psicologia, visando a proteção da saúde e do bemestar do paciente, tendo sido necessário, ocorrer isto neste estudo, para que a paciente se mantivesse segura.

Este tipo de intervenção pontual, após tentativa, possui como objetivo proporcionar apoio ao paciente, reduzir o risco de tentativa posterior de suicídio, compreender a situação atual, nomear contatos de segurança e medidas a serem tomadas, assim como ser realizados os devidos encaminhamentos. Constando-se a necessidade da paciente ser encaminhada para atendimento psicológico, a mesma deu seguimento no processo terapêutico, conduzido por uma das estagiárias participantes na intervenção.

Como fatores limitantes deste estudo, aponta-se para a dificuldade de encontrar artigos de revisão recentes em periódicos nacionais que abordem o tema de suicídio, além de ser percebido que artigos de relato de experiência e intervenções neste tipo de atendimento são inexistentes, constando-se assim, a importância de haver maiores estudos que aprofundem esta temática. Ainda, a troca de conhecimentos sobre atendimento a pacientes em crise realizados por estudantes de graduação de Psicologia ou profissionais, podem ser de grande contribuição para a formação posterior de outros profissionais da área da saúde.

\section{Referências}

Barbosa, F. O., Macedo, P. C. M., \& Silveira, R. M. C. (2011). Depressão e o suicídio. Revista da SBPH, 14(1), $233-243$.

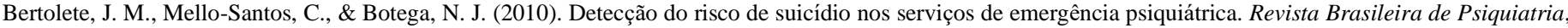
v. 32 (2): 587-595.

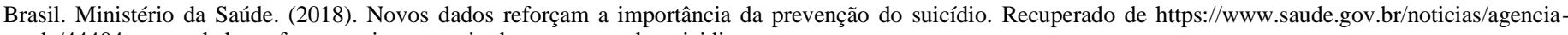
saude/44404-novos-dados-reforcam-a-importancia-da-prevencao-do-suicidio.

Brasil. Ministério da Saúde. (2009). Prevenção do suicídio: Manual dirigido a profissionais da saúde da atenção básica. Brasília: OPAS/ Unicamp.

Brasil. Ministério da Saúde. (2020). Suicídio na Pandemia Covid-19.. Brasília: Fundação Oswaldo Cruz.

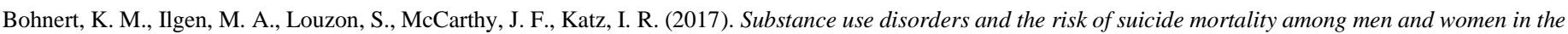
US Veterans Health Administration. Addiction. 112(7):1193-1201

Botega, J. N. (2015). Crise suicida: Avaliação e manejo. Porto Alegre, Rs: Artmed.

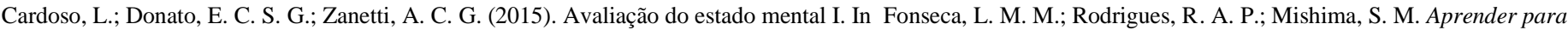
cuidar em enfermagem: situações específicas de aprendizagem (21-26). Ribeirão Preto: USP/EERP..

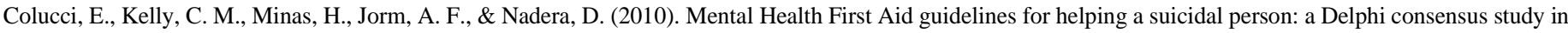
the Philippines. International Journal of Mental Health Systems, 4(1):32. 
Research, Society and Development, v. 10, n. 15, e74101522769, 2021

(CC BY 4.0) | ISSN 2525-3409 | DOI: http://dx.doi.org/10.33448/rsd-v10i15.22769

Conselho Federal de Psicologia. (2013). O Suicídio e os Desafios para a Psicologia. Brasília, DF: CFP.

Conselho Federal de Psicologia. (2005). Resolução CFP nº 010/2005. Código de Ética Profissional do Psicólogo, XIII Plenário. Brasília, DF: CFP.

Conselho Regional de Psicologia do Rio Grande do Sul. (2019). A Psicoterapia na prática: cartilha de orientação. Porto Alegre, RS: CRP.

Fam, B. M.; Ferreira Neto, J. L. (2019) Análise das Práticas de uma Clínica-Escola de Psicologia: Potências e Desafios Contemporâneos. Psicologia: Ciência e Profissão, 39, 1-16.

Friedberg, R. D., \& McClure, J. M. (2019). A prática clínica da terapia cognitiva com crianças e adolescentes. (2ª edição). Porto Alegre: Artmed.

Fukumitsu, K. O. (2014). O psicoterapeuta diante do comportamento suicida. Psicologia USP, 25(3), 270-275.

Gil, A. C. (2002). Como elaborar projetos de pesquisa. São Paulo, SP: Atlas.

Gondim, P. D. S. M. (2015). A intervenção da Psicologia: Tentativas de suicídio e urgência hospitalar. Revista Científica da FMC, 10 (2):12-16.

Gooding P. A., Pratt, D., Awenat Y., Drake, R., Elliott, R., Emsley, R., ... Haddock, G. (2020). A psychological intervention for suicide applied to non-affective psychosis: the CARMS (Cognitive Approaches to Combatting Suicidality) randomised controlled trial protocol. BMC Psychiatry; 20 (11):306.

Hawton, K., Witt, K. G., Taylor-Salisbury, T. L., Arensman, E., Gunnell, D., Hazell, P., ... Heeringen, K. V. (2016). Psychosocial interventions for self-harm in adults (review). Cochrane Database Syst Rev.; 5:1-308.

Klonsky, E. D., May, A. M., \& Saffer, B. Y. (2016). Suicide, Suicide Attempts, and Suicidal Ideation. Annual Review of Clinical Psychology, 12(1), 307-330.

Maia, R. S., Rocha, M. M. O., Araújo, T. C. S., \& Maia, E. M. C. (2017). Comportamento suicida: reflexões para profissionais de saúde. Rev. Bras. Psicoter. 19(3): $33-42$

Martins, R. M. \& Cassel, P. A. (2019). Intervenção na crise suicida: elaboração de um protocolo de entrevista e observação clínica para a avaliação e manejo da crise suicida em paciente de clínica escola de psicologia. (Trabalho de conclusão de curso). Universidade Franciscana - UFN, Santa Maria, RS, Brasil.

Nogueira, C. A., Crisostomo, K. N., Souza, R. S., \& Prado, J. M. (2017). A importância da psicoeducação na terapia cognitivo-comportamental: uma revisão sistemática. Rev. Higia. 2(1): 108-120.

Oliveira, C. T., \& Dias, A. C. G. (2018). Psicoeducação do transtorno do déficit de atenção/hiperatividade: o que, como e para quem informar?. Temas em Psicologia, $26(11), 243-261$.

Organização Mundial da Saúde. (2000). Prevenção do suicídio: um manual para médicos clínicos gerais. Genebra: World Health Organization.

Organização Pan-Americana de Saúde. (2018). Folha Informativa - Suicídio.

Osteen, P. J., Frey, J. J., Ko, J. (2014). Advancing Training to Identify, Intervene, and Follow Up with Individuals at Risk for Suicide Through Research. American Journal of Preventive Medicine, 47(3), 216-221

Palma, D. C. A., Santos, E. S., \& Ignotti, E. (2020). Análise dos padrões espaciais e caracterização dos suicídios no Brasil entre 1990 e 2015. Cadernos de Saúde Pública, 36(4), 1-13.

Patias, N. D., Hohendorff, J. V. (2019). Critérios de qualidade para artigos de pesquisa qualitativa. Psicologia em Estudo. 42, 1-14.

Peres, R. S., Santos, M. A., \& Coelho, H. M. B. (2004). Perfil da clientela de um programa de pronto-atendimento psicológico a estudantes universitários. Psicologia em Estudo, 9(1), 47-54.

Rocha, N, K., \& Araújo, N. G. (2018). Suicídio: Identificando e Fortalecendo Fatores Protetivos. In Araújo, N. G., Rubino, J. P., \& Oliveira, M. I. S. (Orgs.) Avaliação e intervenção na clínica em Terapia Cognitivo-Comportamental: a prática ilustrada (217-245). Novo Hamburgo: Sinopsys Editora

Sá, S. D., Werlang, B. S. G., \& Paranhos, M. E. (2008). Intervenção em crise. Rev. Bras. de Terapias Cognitivas. 4(1), 8-20.

Sher, L., \& Khan, R. S. (2019). Suicide in Schizophrenia: An Educational Overview. Medicina (Kaunas), 55(7): 361.

Sousa Filho, D., Kanomata, E. Y., Feldman, R. J., \& Maluf Neto, A. (2017) Avaliação e manejo do paciente com risco de suicídio. In Kernkraut, A. M., Silva, A. L. M., \& Gibello, J. O psicólogo no hospital: da prática assistencial à gestão de serviço. (119-134). São Paulo, SP: Edgard Blucher.

Tureki, G., Brent, D. A., Gunnel, D., O’Connor, R. O., Oquendo, M. A., Pirkis, J., \& Stanley, B. H. (2019). Suicide and suicide risk. Nat. Rev. Dis. Primer. 74(5), 122.

Wenzel, A., Brown, G., \& Beck, A. T. (2010). Terapia Cognitivo-Comportamental para pacientes suicidas. Porto Alegre: Artmed.

Werlang, B. S. G., Borges, V. R., \& Fensterseifer, L. (2005). Fatores de risco ou proteção para a presença de ideação suicida na adolescência. Revista Interamericana de psicologia, 39(2), 259-266.

World Health Organization. (2019). Suicide. Genebra: World Health Organization. Recuperado de https://www.who.int/news-room/fact-sheets/detail/suicide. 
Research, Society and Development, v. 10, n. 15, e74101522769, 2021

(CC BY 4.0) | ISSN 2525-3409 | DOI: http://dx.doi.org/10.33448/rsd-v10i15.22769

World Health Organization. (2019). Suicide in the world: Global Health Estimates. Genebra: World Health Organization. Recuperado de https://www.who.int/publications/i/item/suicide-in-the-world.

Wright, J. H., Brown, G. K., Thase, M., \& Basco, M. R. (2019). Aprendendo a terapia cognitivo-comportamental: um guia ilustrado. (2 a edição). Porto Alegre: Artmed.

Yatham, L. N., Kennedy, S. H., Parikh, S. V., Schaffer, A., Bond, D. J., Frey, B. N., ... Berk, M. (2018). Canadian Network for Mood and Anxiety Treatments (CANMAT) and International Society for Bipolar Disorders (ISBD) 2018 guidelines for the management of patients with bipolar disorder. Bipolar Disord. 20(2):97170.

Zana, A. R. O., \& Kovács, M. J. (2013). O Psicólogo e o atendimento a pacientes com ideação ou tentativa de suicídio. Estudos e Pesquisas em Psicologia, 13(3), $897-921$. 